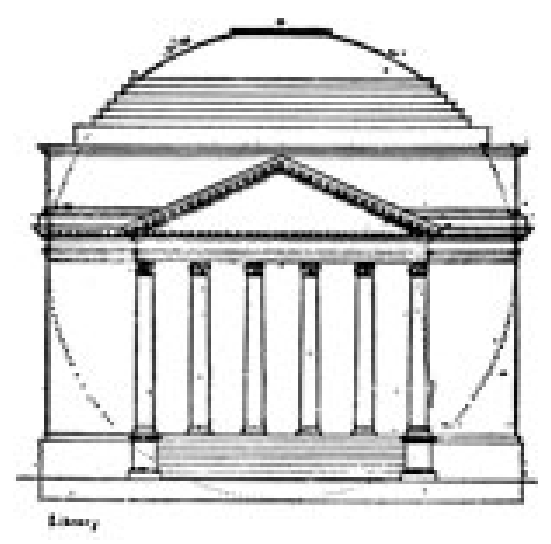

Agenda Influence and Its Implications

Author(s): Michael E. Levine and Charles R. Plott

Reviewed work(s):

Source: Virginia Law Review, Vol. 63, No. 4 (May, 1977), pp. 561-604

Published by: Virginia Law Review

Stable URL: http://www.jstor.org/stable/1072445

Accessed: 15/01/2013 14:51

Your use of the JSTOR archive indicates your acceptance of the Terms \& Conditions of Use, available at http://www.jstor.org/page/info/about/policies/terms.jsp

JSTOR is a not-for-profit service that helps scholars, researchers, and students discover, use, and build upon a wide range of content in a trusted digital archive. We use information technology and tools to increase productivity and facilitate new forms of scholarship. For more information about JSTOR, please contact support@jstor.org. 


\title{
AGENDA INFLUENCE AND ITS IMPLICATIONS $\dagger$
}

\author{
Michael E. Levine* and Charles R. Plott**
}

\section{The Problem}

W HEN choosing from many competing alternatives, groups often narrow the range of choice and then select from the remaining alternatives using a predetermined procedure or agenda. ${ }^{1}$ In some groups, this process may involve the use of committee reports and parliamentary procedure. In others, choices may be narrowed by common consent, by the chairman, or by some other means and "voting" may proceed in a predetermined, nonparliamentary fashion. Recent developments in the theory of group choice (embodied in a literature that has come to be known as the "social choice" literature) suggest that there probably is no single nondictatorial method of aggregating the preferences of an electorate that will reliably produce a choice which satisfies minimal consistency and rationality standards. ${ }^{2}$ Since reasonably plausible

+ Support for this research was supplied by the Henry Luce Foundation and the National Science Foundation.

The authors gratefully acknowledge the helpful suggestions provided by members of the USC Law Center Faculty Workshop, and the particularly helpful comments of S.H. Bice, R.P. Burton, A. Schwartz, L. Simon, and C. Wolfram. At various stages, our work was also presented to the Law-Economics Workshop at UCLA and the Legal Theory Workshop at Yale. We appreciate the opportunity afforded us by those workshops to refine our presentation. Steven Matthews, Caltech graduate student in social science, provided invaluable assistance on the project, and Michael $\mathrm{J}$. Graetz provided both encouragement and important contributions at difficult moments in the evolution of this work. Despite all this assistance, review and refinement, errors, regrettably, probably persist. We grudgingly accept responsibility for all of them.

* Henry R. Luce Professor of Law and Social Change in the Technological Society, California Institute of Technology; and Professor of Law, University of Southern California.

** Professor of Economics, California Institute of Technology.

1 In this article, we mean by an "agenda" a series of alternative choices on which the group votes.

2 This literature grew out of attempts to define a "social welfare" function that would enable a democratic society to choose rationally among alternatives which benefited some and disadvantaged others. In a series of explorations (which led to a Nobel Prize in Economics), Professor K.J. Arrow established his famous "General Possibility Theorem," which can be interpreted as saying that no possible system of combining the preferences of the individuals in a society produces results that are both nondictatorial (democratic) and consistently rational. For a statement of the General Possibility Theorem, see $\mathrm{K}$. 
examples of paradoxical results can be developed for each commonly used system of preference aggregation, such as majority rule or preferential point voting, ${ }^{3}$ there is probably no single process that "best" reflects the "will" of the group. The social choice literature also tells us that the outcome of any given attempt to determine a group choice theoretically depends upon the particular method used, ${ }^{4}$ but reliable evidence for this proposition has been sparse indeed.

ARrow, Social Choice and Individual Values 96-100 (2d ed. 1963). An entire literature has grown out of this effort, consisting mostly of attempts to escape the rather depressing implications of this theorem and of attempts to identify the range of circumstances to which it applies.

As originally formulated, Arrow's result was extremely general. For example, it required a social welfare function to be able to accommodate any combination of individual preferences and still define unambiguously and consistently social choices over the entire set of feasible alternatives. This was both the source of its power and (some thought) the likely source of its ultimate vulnerability to criticism on the ground that it asked more than any real-world society would demand of a system of social choice. However, attempts to sabotage the theory or to weaken its implications (for example, by restricting the domain of alternatives that it must order or by excluding certain individual preference patterns from consideration) have not been nearly as successful as originally hoped. See Plott, Axiomatic Social Choice Theory: An Overview and Interpretation, 20 Aм. J. Pol. SCI. 511 (1976). Efforts along these lines continue, but the prognosis is guarded.

The ambiguities and possibilities for paradox postulated by the general impossibility result are the ultimate underpinnings of our model. Obviously, if there exists a foolproof method to identify and to reach the unambiguous preference of a group, such a method (by definition) would be immune to influence from the order and groupings in which alternatives were presented. What the Arrow Theorem and its progeny suggest to us is that there is no such method. If there is no way of uniquely defining a social preference, then it must be the case that two or more inconsistent outcomes are possible from any individual preference configuration. If this is the case, there must be associated with each inconsistent alternative a procedure by which it can be reached. In other words, our effort starts from the proposition that in principle there is for each instance of a group choice over which there is conflict more than one procedure to resolve it, and that these procedures will often produce different outcomes.

For a general review of the social choice literature and its implications, see P. Fishburn, The Theory of Social Choice (1973); A. Sen, Collective Choice and Social Welfare (1970); Mueller, Public Choice: A Survey, 14 J. Econ. Literature 395 (1976); Plott, supra.

3 See Fishburn, Paradoxes of Voting, 68 A M. Pol. ScI. Rev. 537 (1974); Plott, supra note 2 , at 513-17.

4 In his Theory of Committees and Elections (1958), R.D. Black discusses, among other matters related to the subject of this article, the effects on some group decisions of the order of considering issues, the exploitation of cyclical majorities, the timing of proposals, and the phenomenon of strategic voting. This important early work foreshadows some of our own effort, but focuses on specific instances, such as majority-rule cycles, and does not recognize the generalized influence of the agenda on all situations involving intragroup conflict. 
This problem ought to interest legal theorists as well as economists and political scientists. Many legal processes share important features with processes whose consistency and neutrality are called into question by this literature. Notions such as "legislative intent" or "statutory purpose" seem to be based on the outcomes of processes whose consistency and neutrality have been placed in doubt by theoretical scrutiny. Decisionmaking by multi-judge appellate courts, jury deliberations, pretrial settlement negotiations and issue stipulations, and several varieties of administrative determination (including the very popular hearing examinervoting commission method of issue resolution) display features that may make them vulnerable to similar theoretical criticism. If the legitimacy of legal procedures depends even in part on the premise that procedure is a neutral midwife to the genesis of an institution's substantive decisions, ${ }^{5}$ then the specification of important, even determinative, procedural influences on outcomes may be of considerable practical and jurisprudential importance. While the assumption that procedures can influence outcomes will certainly not shock any reasonably sophisticated legal observer or participant, the degree of procedural influence posited by the social choice literature and the predicted difficulty of neutralizing it might well come as something of a surprise even to the sophisticated advocate of "fair" procedures.

That life in society is complex and often unfair and that choices are frequently hard is probably no cause for acute alarm, however much these facts may justify a chronic low-grade melancholia. In this light, one might view theoretical proofs ${ }^{6}$ of problems inherent in certain techniques of group choice as a general caution against overconfidence in the integrity of widely accepted procedures. Once cautioned, one might downplay the significance of these proofs for the evaluation of existing social processes. And one who intuitively or casually accepts the likelihood of procedural and, in par-

5 The desirability of neutral procedure is an assumption widely shared in the legal literature. See, e.g., 8 Moore's Federal Practice q2.02 (1976).

Social-scientific investigations of procedural influences on outcomes have assumed that procedural neutrality was a socially desired goal. $\rightarrow$ Thibaut, Walker, LaTour \& Houlden, Procedural Justice as Fairness, 26 STAN. L. Rfv. 1271, 1271-75 (1974); Walker, Thibaut \& Andreoli, Order of Presentation at Trial, 82 YALE L.J. 216 (1972).

6 E.g., K. Arrow, supra note 2; P. Fishburn, supra note 2; A. Sen, supra note 2; Plott, supra note 2 . 
ticular, agenda influence might well regard more formal assertions of such influence as probably true, but unsurprising and manageable in most contexts. But if the principles found in the social choice literature could be used systematically and predictably in specific situations to affect dramatically the outcome of a seemingly fair choice procedure, for example by controlling the agenda used, and if this influence could be effected in ways that exhibited no obvious manipulation or unfairness, this might justify careful examination of other choice procedures, including some important legal processes, to see if they are similarly vulnerable.

Before urging anyone to worry about legal processes in general or any legal process in particular, we needed to satisfy a reasonably skeptical audience, including ourselves, that social choice theory could be applied to influence outcomes through processes that appeared acceptably fair to participants. We had an opportunity to explore this possibility in the case of a large flying club selecting a new fleet of planes for members to fly. We then applied our theory in laboratory experiments, described briefly below and reported in detail elsewhere. ${ }^{7}$ Both the flying club meeting and the laboratory experiments confirmed the applicability of the model we now describe.

As a result of this investigation, we make two general claims. First, the agenda or groupings in which alternatives are considered for adoption or elimination can be a major parameter in determining what a group will ultimately choose. Second, the nature of this influence is sufficiently systematic to yield to an analytical model. These conclusions may have important practical and ethical implications.

\section{ThE THEORY}

The theory we used is simple. An agenda influences outcomes in two ways. First, it limits the information available to individual decisionmakers about the patterns of preference in the group. A primary means available for preference revelation in a large group is voting, and the form of the agenda specifies the content of each

7 Plott \& Levine, A Model of Agenda Influence on Committee Decisions, 68 Am. Econ. REv. - (1978) (manuscript on file in the offices of the Virginia Law Review Association) (references herein derived from prepublication manuscript). 
vote. In some settings, other means of preference revelation such as verbal communication or straw votes can be ruled "out of order" by rigorous germaneness rules or by strict adherence to an agenda and therefore are of limited use in communicating preference information to other voters. In other settings, where there are many alternatives and many participants, such activities may be of limited importance even when they are permitted. And even in smaller groups where discussion is extensive and repeated often over time (a faculty meeting, for example), positions on any particular alternative may be sufficiently hard to predict that voting is the most relied-on indicator of "true" preferences.

In addition, on-the-spot coordination of decisions among individuals through binding agreements is nearly impossible in most meetings. This generally precludes collusive behavior unless it is the result of a premeeting meeting. Even then, to be effective in planning strategy, the coalition would have to be very well-informed about both the patterns of preference within the group and the agenda to be used.

Thus, each individual usually finds himself in a position of, and his behavior will be consistent with theories about, decisionmaking under uncertainty. His subjective probabilities about the actions of the group may range from favorable ("From any set, the group is likely to choose the thing I want most") to unfavorable ("From any set, the group will always choose what I want least"), but aside from such "world views," the preferences of others often will have limited opportunity to influence his behavior.

Second, the agenda determines the set of strategies available to the individual. He can attempt to choose among outcomes; but the agenda determines at any point the outcomes among which he may choose. The individual always must pick the particular strategy he prefers from among those available; the agenda determines the available set of strategies. So, by controlling the influence of others' preferences and by determining the set of strategies available to him, the agenda effectively influences the voting pattern of each individual in the group. It thereby influences the choice made by the group. ${ }^{8}$

8 We think that the agenda is a very important parameter in determining the outcome of group decisions. In addition we feel we have a rudimentary understanding of the princi- 


\section{ThE MODEL ${ }^{9}$ \\ A. The Agenda}

The form of agenda we used in our analysis can be represented abstractly as a series of partitions of the feasible set of alternatives into two sets. Each item on the agenda eliminates some set of alternatives from further consideration.

We used the following example to explain the operation of an agenda to some experimental groups. Suppose that the question is what kind of banquet to give. One agenda reads: "Item 1. Shall the dress be formal or informal? Item 2. Shall the cuisine be French or Mexican?" This agenda is modeled by the following diagram:

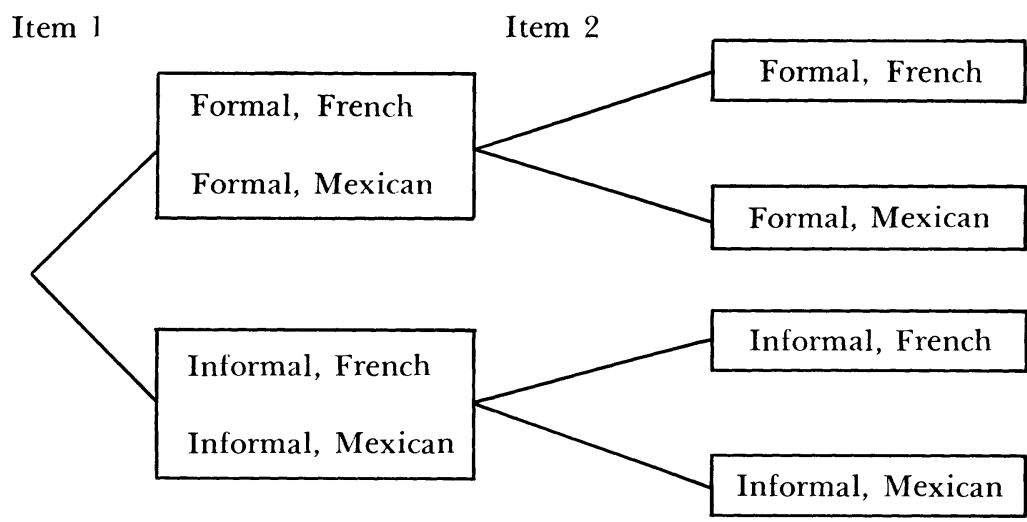

Another agenda might reverse these items, requiring the group to vote first on cuisine and then on attire. This agenda could be modeled as follows:

ples underlying agenda influence. These are spelled out more precisely in our model. But given the limitations of our data and the crudeness of our theory, we are not prepared to assert that the principles we use are the only principles of agenda influence or that our statement of these principles is entirely accurate. For a more detailed discussion of the inaccuracies of our model, see Plott \& Levine, supra note 7.

How then to make our point about the nonneutrality of the agenda? We attempted to do so empirically. However, readymade situations like the flying club where we had a good knowledge of preferences and an opportunity to exercise agenda influence were difficult to find. The flying club example standing alone is insufficient evidence because the result achieved is consistent with many competing hypotheses that cannot be discredited with available information. We tried to overcome these problems by turning to laboratory experiments.

9 For a more formal and detailed statement of our model, see Plott \& Levine, supra note 7 , at - - . 


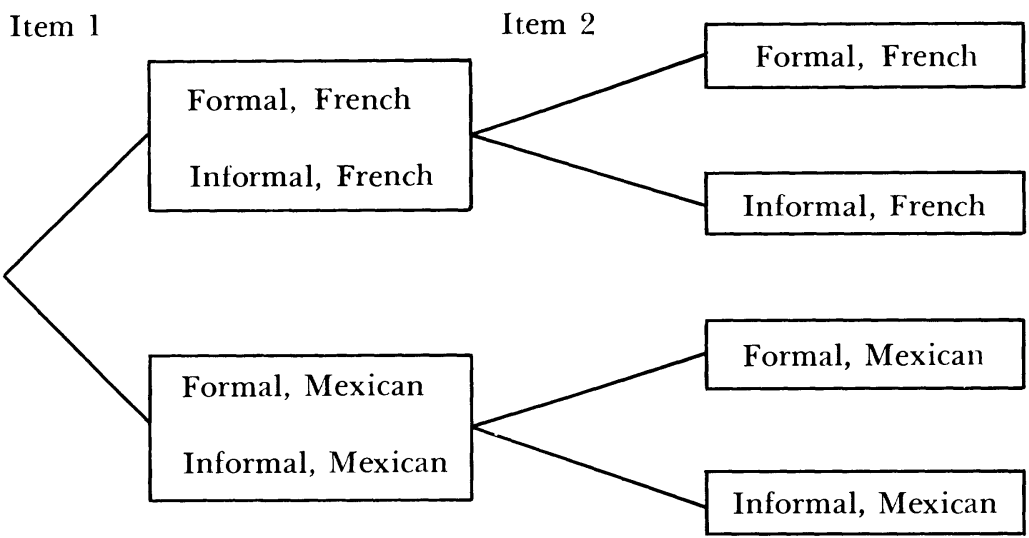

These diagrams resemble the "trees" used to represent the choices faced by individuals making decisions under conditions of uncertainty. ${ }^{10}$ Each "tree" that can be formed from a given set of alternatives represents a different agenda. For a fixed set of alternatives, the set of all agendas corresponds to the set of all such "trees."

There may be a practical limit to the number of "trees" available for use in resolving a given choice problem. Not all possible "trees" may correspond to an agenda presenting a "natural" appearing set of choices. Take the banquet problem just presented: How would one word Items 1 and 2 to yield an agenda corresponding to the following "tree"?

Item 1

Item 2

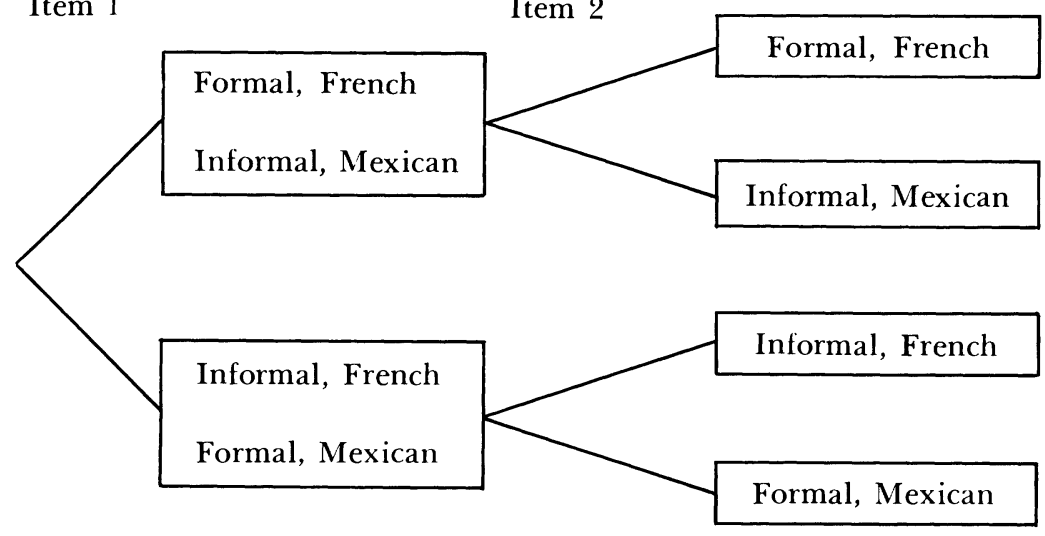

10 See H. Raiffa, Decision Analysis 10-13 (1968). 
No really convincing representations occur to us. One might try listing them on a page (perhaps as a written agenda) in the order: (1) French, formal, (2) Mexican, informal, (3) French, informal, (4) Mexican, formal. Item 1 would then be: "Would we prefer one of the first two alternatives or one of the second two?" Item 2 would be: "Which of the two remaining do we want?" The artificiality of this agenda exemplifies the problem. We know of no general solution. But in most situations, a wide choice of "natural" appearing agendas is available. As one bit of evidence we can report that after many experimental instances, we have not yet had the "naturalness" of an agenda questioned, but experimental subjects are probably more tolerant of "unnatural" agendas than realworld decisionmakers. We suspect that, given a particular configuration of individual preferences, some results cannot be reached using a "natural" appearing agenda.

\section{B. Individual Preferences}

Each individual faced with a choice among several possible group outcomes assesses the desirability of each alternative from his own perspective. He assigns a "payoff" value to each possible outcome and ranks them in order of preference. The final selection by the group thus determines each member's payoff, which may of course differ among individuals. To estimate the effect of an agenda on an outcome, it is necessary to have at least some approximation of the preferences of the individual group members. In the flying club experiment described below, estimates of individual preferences were based on the familiarity of one of the experimenters with the group, on previous statements by group members, and on the results of a questionnaire (not designed by the experimenters) circulated among the membership. In our laboratory experiments, we assigned each participant a monetary payoff for each possible outcome.

\section{Individual Voting Rules}

How does an individual choose among alternatives? What decision rules will he use? In our experimental investigations, we postulated a universe of three different decision rules.

The sincere-voting hypothesis. This hypothesis holds that an individual faced with two sets of alternatives will vote for the set 
that contains his most preferred alternative. If he is indifferent between the two best alternatives, he decides on the basis of a comparison between the second-ranked alternatives. If he is indifferent between these two, then the rule does not tell us which of the alternatives he will choose.

The avoid-the-worst hypothesis. Here the individual votes to avoid the alternatives he likes the least. When faced with a choice between two sets, he compares the least preferred alternative in each set and votes against the set in which the worse of these two alternatives appears. The case of ties is treated as above.

The average value hypothesis. This hypothesis holds that the individual treats the group choice as a lottery that will choose any alternative in a particular set with equal probability. The choice between two sets is like a choice between two lotteries (with a uniform distribution over the outcomes) and he chooses (votes for) the one with the higher expected value. Since the payoffs of these alternatives are in terms of money, the theory says he will choose the set with the highest average payoff. The case of ties is treated as above.

Clearly, these three decision rules do not exhaust the set of imaginable decision rules. Any of them, for example, could be expanded to take into account the variance of the payoffs in a set or to reflect differing attitudes toward risk. Any of them could be modified to include past decisions made by the group as well as subjective estimates of future decisions. Nevertheless, these rules form the backbone of our model. We know that the model could stand improvement and suspect that this is one of the places where improvement can be achieved.

For the purpose of constructing agendas, we adopted two axioms. Axiom 1: Independence From Environment.

This means that the individual does not act strategically by anticipating upcoming votes. His probability of voting also is not affected by previous votes, by discussion at any stage of the meeting, by set sizes, or by other such factors. We assume that he always uses one of the decision rules above and that he chooses from among them with fixed probabilities. ${ }^{11}$

11 This axiom is obviously an important simplifying assumption. The model does not take into account instances of strategic voting, which may well be an important practical factor in particular circumstances. Our experience with the flying club and the laboratory experiments, however, suggests that useful predictions can be made even with this admittedly crude assumption. 
Axiom 2: Stochastically Identical Individuals.

This axiom postulates a certain similarity among individuals. It says that any individual with a particular set of preferences facing a particular set of alternatives votes according to the same probabilities as anyone else with those same preferences who finds himself in that same situation. (In addition, this axiom declares that the number of possible interactions between decision rules and alternatives can be specified.)

\section{The Sirength of One Alternative Against Another}

To calculate the likelihood that an agenda will yield a desired result, one must first know the strength of one alternative against another at each point in the agenda. Suppose that the voting rule is majority rule and that the agenda has pitted one set of alternatives against another. What is the probability that one set will win? This probability will be called the "strength" of one set of alternatives against another (and can be calculated).

\section{E. Strength of an Agenda}

This is the model of primary interest. What agenda is most likely to yield a given alternative as the group's choice? To answer this question one must calculate the probability under any specified agenda that the alternative in question will be the group's choice. This is done by calculating the probability that any given individual will vote one way or the other on each partition. By aggregating these probabilities one can calculate the probability that some majority of individuals will vote a particular way at each partition. The probability that any given final alternative will be reached using an agenda (called the "strength" of the agenda for that alternative) is the combined probability that the group will choose the required alternative at each point in the decision process. With that formula in hand, one can then survey all possible agendas (which incidentally is no simple problem) to find the one that maximizes the chance of getting the alternative.

\section{Influencing The Group}

Applying the theory raises three more problems. The first involves obtaining estimates of the probability that an individual 
will make a particular voting choice, given described preferences and several possible decision rules. The probabilities used in our experiments were estimated from pilot experiments.

The second problem involves the interesting mathematical problem of finding the optimum agenda. For each alternative, one can compute the probability that it will win under any given agenda. For a would-be manipulator, choosing an agenda is like choosing from among lottery tickets with different amounts of risk and different payoffs. Which agenda is "best" depends upon how one values such attributes as the likelihood of positive or very unfavorable results, attitudes toward risk, and ease of presentation. In our experiments, we simply chose the agenda with the highest probability of yielding the desired result.

Third, for the theory to be confirmed, the group must adopt and adhere to an agenda. For a manipulator, this involves devising an adoptable agenda that presents choices in an acceptable or "natural" way and preventing alternative motions from reaching the floor.

\section{The Flying Club Experiment}

We applied this theory to our flying club. ${ }^{12}$ Our group had flown a fleet of five to six single-engined planes for a number of years. At the time of this study, a decision had been made to replace the group's existing fleet of planes. The range of feasible alternatives for the group was large, because revenue from the sale of some of the aircraft together with a loan that the club could easily obtain would enable the club to choose among a wide variety of types and fleet sizes without additional capital levies on the membership.

Selecting among possible alternatives was complicated by differing tastes among members, differences in willingness to pay higher rates, tax problems related to previous depreciation policies, and political differences between members of the group and the club's board of directors. What fleet of planes should the club buy?

A formal meeting of the group was called to advise the club's

12 A flying club is a nonprofit organization that purchases and maintains a fleet of airplanes to rent to its members. The particular group discussed in the text has about sixtyfive members. 
board on the future size and composition of the fleet. The advisory selection was to be made by a vote of the membership at the meeting, and one of us was responsible for devising an agenda that would allow deliberations to proceed in some orderly fashion. This was no simple task: there were many alternatives, there were over fifty members, and tastes were strongly held and differed radically among members of the club.

By the time of the meeting the universe of available aircraft had been narrowed to four alternative aircraft types. These aircraft differed in cost, speed, capacity, and configuration. While the ultimate decision regarding rental fees would be made by the club's board of directors, who frequently decided matters independently of the expressed preferences of the group, it is safe to assume that members expected that higher aircraft costs would be reflected in the rental fee for the particular airplanes chosen.

Theory told us that there were many "good" procedures (acceptably fair by normal criteria and linked systematically to the preferences of the individuals in the group) and no uniquely "best" procedure. Since we thought that different "good" agendas would produce different outcomes, we decided to adopt the "good" procedure most likely to get the group to choose the fleet of planes we preferred. Our motivations were a mixture of a desire to test empirically the implications of a promising body of theory and a desire, all other things being equal, to have at our disposal the fleet of planes that best suited our tastes. ${ }^{13}$ Our experiment was rather crude because the theory was not fully developed, we were under some time pressure, and our initial data left something to be desired.

We first specified our own preferences, both as to aircraft type (here identified by letter as A, C, E, and F) and as to fleet size. Our

13 The authors have been criticized on ethical grounds for conducting a real-world experiment on unknowing subjects. Upon reflection, we tentatively conclude that manipulating real-world meetings for experimental purposes is ethically suspect only in the instance of nondisclosed exploitation of "fiduciary" opportunities to structure the agenda for private gain. Other circumstances in which agenda influence may play a part in determining outcomes seem to us to be little different from those conferred by political acumen, rhetorical skill, or knowledge of the preferences of group members. We remain open, however, to identifications of particular circumstances in which "real" or experimental exploitation of the agenda phenomenon may result in fundamental unfairness. 
most preferred alternative was a seven-plane fleet consisting of three E's, plus either two more E's or two F's, and two C's. We were particularly anxious to have at least one $\mathrm{C}$ included (it has six seats, while E's and F's have only four), and we wished to avoid including A's (they have six seats, but are too expensive for us). Our ordering then was (where $\sim$ indicates indifference):

(1) EEEEECC $\sim$ EEEFFCC

(2) EEEEEC $\sim$ EEEFFC

(3) EEEEEA $\sim$ EEEFFA

(4) EEEEEAA $\sim$ EEEFFAA

Our second order of business was to design an agenda that would get us the fleet we wanted. This meant that we had to (l) estimate the pattern of preferences among group members, (2) theorize about their possible voting behavior, and (3) construct an agenda that simultaneously was "fair" and afforded us the maximum possible advantage.

We were not without some solid information about preferences. Several preliminary committee meetings had been held with varying numbers of members present. A questionnaire had been circulated, and while it did not yield exactly the information we wanted, it did give us some estimates about the pattern of preferences.

Our initial estimates of membership preferences indicated that we had a very difficult job indeed. Most members seemed to prefer a fleet consisting entirely of E's or F's (E's and F's are older and newer models of the same basic type). Further, although most were anxious to keep costs down, many of those preferred operating some more expensive F's to operating C's, which were less expensive than F's. We decided to construct a process designed to eliminate certain alternatives by confronting those alternatives with coalitions of less popular alternatives. The group would commit itself to follow those steps by adopting an agenda. This agenda was designed before our model was fully developed. In designing this agenda, we hypothesized that people would follow one of two decision rules: they would either vote for the set that contained their most preferred alternative, or they would vote against the set that contained their least preferred alternative. (We systematically used only the former.) 


\section{Figure 1 \\ Flying Glub Agenda}

This is the agenda for the Group 111 equipment meeting. Your subcommittee has tried to define a series of problems facing the group and to give you an opportunity to express your preferences in resolving them. We suggest that you take a few moments to look over this agenda and familarize yourselves with the choices facing us, then come to the meeting, participate in the discussion, and vote by show of hands on the choices presented in alternatives 2-6. We would like to present the Board with the most comprehensive possible expression of Group 111 opinion. Please come.

1. INTRODUCTION:

Availability, Type variety, Previous Depreciation problems, Needs of the Group vs. Cost, Safety, Radio Equipment.

2. PRIMARY AIRCRAFT TYPE:

PROBLEM: Survey suggests that many Group 111 members prefer that the main part of the group fleet be four-seat Bonanzas. Should these be all the same age? If so, we could sell all existing Bonanzas and buy new F-33A's or we could sell only the V and F and buy used E-33A's. If they can be different ages, should we keep our E's and add new F's? Or do we want C-210's? Previous depreciation practices may affect these choices.

INPUTS:

Costs and rates for new F-33A's and refurbished E-33A's.

Depreciation problems.

Maintenance comparisons.

Availability and price of used aircraft.

VOTE: PRIMARY FLEET TYPE SHOULD BE:

a. All new F-33A's at about $\$ 29.00$ hour;

b. Refurbished E-33A's at about $\$ 24.00$ hour;

c. Mixed new F-33A's at about $\$ 28.00$ hour and refurbished F-33A's at about $\$ 24.00$ hour;

d. New C-210's at about $\$ 25.00$ hour.

3. SIZE OF GROUP 111 FLEET:

PROBLEM: Survey suggests that membership considers present availability to be unsatisfactory. This summer we operated with a little over five aircraft available. We have based our rates on $500 \mathrm{hrs}$./yr./aircraft. With only five aircraft available, we are flying more than that. We can clearly operate six aircraft at $500 \mathrm{hrs}$./yr./aircraft. We might be able to operate seven at that rate. We almost certainly couldn't operate eight at 500. If we assume, conservatively, that a seventh aircraft would operate 400 hours and an eighth 300 hours, the question becomes, "how much availability do we want to pay for?"

INPUTS:

Alternative ways of paying for availability.

VOTE:

Cost increases associated with availability.
a. 6
b. 7
c. 8 
4. SHOULD THE FLEET INCLUDE AIRCRAFT OTHER THAN THE PRIMARY TYPE?

PROBLEM: Most members indicated an occasional need for a five or six place airplane. Others indicated a desire to fly aircraft other than Bonanzas. There are advantages in scheduling, rate uniformity, majority choice, and type familiarity in keeping the fleet homogeneous. The advantages of operating more than one type include optimizing for different mission requirements and accommodating minority preferences.

INPUT:

Safety aspects of mixed fleets.

Survey input on desire for 5-place, 6-place, and mixed fleet.

VOTE: FLEET SHOULD BE:

a. All primary type;

b. Mixture of mostly primary type and some six-place.

5. IF SOME SIX PLACE SHOULD BE INCLUDED, SHOULD THEY BE BONANZA A-36's or C-210's?

PROBLEM: Each of the two has advantages and disadvantages and different costs.

INPUT:

Weight and Balance and Performance comparisons.

Maintenance comparisons.

A-36 costs and advantages.

C-2 10 costs and advantages.

VOTE: SHOULD SECONDARY AIRPLANES BE:

a. A-36 at about $\$ 31.50$ hour?

b. C-210 at about $\$ 27.00$ hour?

6. ADDITIONAL EQUIPMENT.

PROBLEM: It has been club policy (and probably will be in the future) to equip aircraft alike. Most of the group has indicated a preference for glideslopes, and the cost discussions so far have included them. Others have discussed DME's, radio-coupled autopilots (no altitude hold), and encoding altimeters (to meet Group 1 TCA requirements starting $7 / 1 / 74)$.

INPUT:

Cost and uses of equipment. Increase in cost/hour.

VOTE:

Would you like to have the following equipment if it increased cost per hour by the following amounts?

YES NO

- DME at about $\$-$ Coupled autopilot at about $\$-$ hour.

- Encoding altimeter at about $\$-$ hour.

7. SUMMARY AND RECOMMENDATIONS TO BE MADE TO THE BOARD 
The agenda we constructed included the following questions (translated here from aeronautical jargon):

(1) What type of aircraft should the primary fleet be? This was to be decided by a Borda count (rank-order point voting).$^{14}$

(2) How many planes do we want?

(3) Do we want a mixed fleet?

(4) What type of aircraft should our secondary fleet be?

(5) How elaborately should we equip the aircraft we purchase? This agenda is shown in Figure 1 and represented schematically in Figure 2.

The formulation of each of these agenda items was important. Furthermore, the order in which they came up was, we felt, crucial. We structured the agenda to focus first upon a "primary fleet." If our estimates were correct, the vote would go for a "primary fleet" of mostly inexpensive planes. This, we thought, would put at ease those members who feared being "stuck" with an expensive fleet, making them more agreeable to a seven-plane fleet and more receptive to the idea of operating some six-seat aircraft. The Borda count was used rather than simple balloting because we did not want the group to become aware of the pattern of controversy and thus vote more strategically. This written ballot would also mask the fact that there was not much sentiment for C's. A member basically indifferent on later votes might have been inclined against C's if he thought few wanted them.

We thought many people wanted an unmixed fleet-six four-seat planes (E's or F's) and no six-seat planes (A's or C's). For the next vote we pitted all those people who preferred seven or more fourseat planes and all individuals who preferred one of the mixed-fleet alternatives against all those who wanted only six four-seat planes. We thought the chances of getting a mixed fleet were greater if there were seven planes, and we hoped (although our model does not postulate strategic voting) that this idea would occur to other mixed-fleet advocates who might have preferred a six-plane fleet.

14 This method of voting requires each member of a group to rank the alternatives presented in the order of his preference. Points are then assigned to each ranked alternative (for example, five points for a first-place vote, four points for a second-place vote, and so on) and added together to determine the winning alternative. 
This vote was taken by a show of hands so it would give those who wanted mixed fleets (a possible minority) an opportunity to muster support.

Figure 2

Schematic Representation of Flying Club Agenda

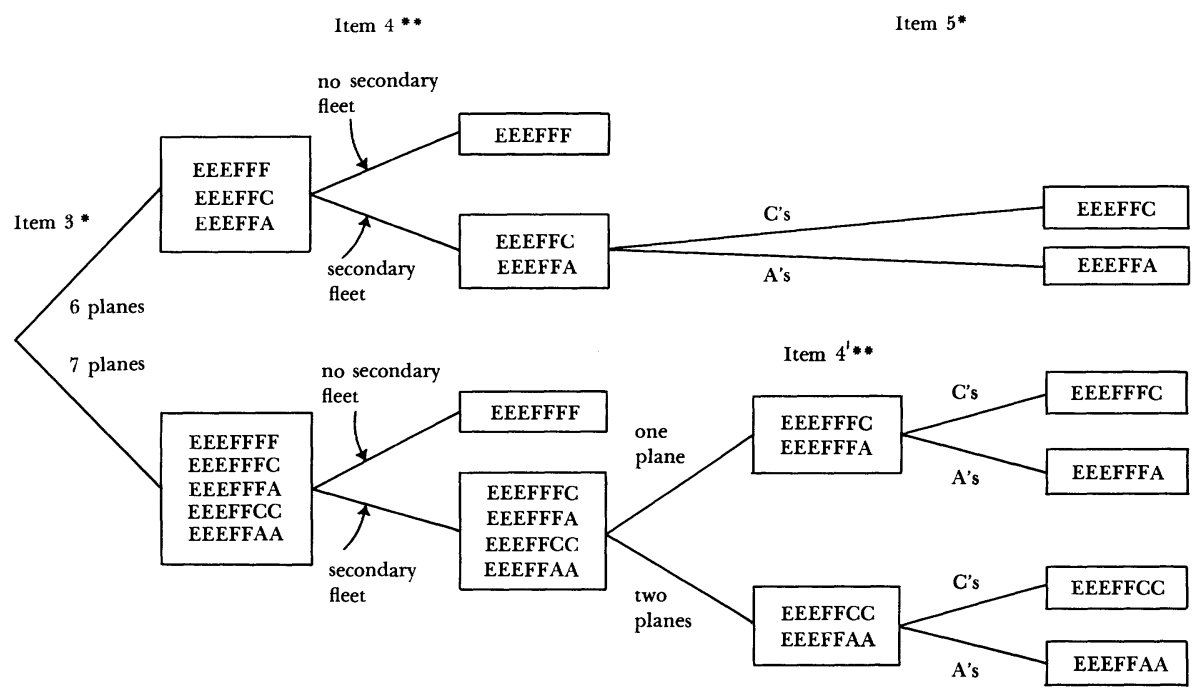

* These item numbers correspond to the numbers on the original agenda.

** The formal agenda listed only Item 4, but the group correctly understood that it had two components - Item 4 and Item 4! At the meeting, the group did not vote formally on Item 4 because no one advocated an unmixed fleet. The group simply moved to consider Item $4^{\prime}$ directly.

The next question was: "Do we want a mixed fleet?" (One involving six-seat planes, either C's or A's). Our initial estimates led us to think that this was the critical vote. We were not certain that there was any particular mixed fleet that could command a majority, so we pitted all people who wanted any kind of mixed fleet against those who wanted all one type. We were not certain 
even that the combined advocates of possible mixed fleets constituted a majority, so we took the vote by a show of hands to give those who wanted mixed fleets a chance to register the intensity of their preferences during the voting. As it turned out, nearly everyone was in favor of a mixed fleet, and this item passed without even a formal vote.

An implicit question was: "How many planes do we want in a secondary fleet?" We thought that any coalition large enough to win the "mixed-fleet" vote would be large enough to vote in at least two six-seat planes. This item did not appear on the formal agenda, but it was implicit in the way the agenda was organized, and it was voted upon. A secondary fleet of two planes was chosen.

The next agenda item was the type of secondary plane. We figured that the high cost of maintaining a seven-plane fleet would make members especially sensitive to costs. Given that they were going to have such a big fleet, most would favor the cheaper of the secondary alternatives-the C's.

A question on avionics equipment was held for last. The rates go up rapidly with additional equipment. If the members had voted in favor of lots of equipment at first, expenses would have been greater and the chances of getting them to choose a sevenplane fleet would have been substantially reduced.

With the exception noted above, the meeting was conducted in accordance with the agenda. The votes went as follows: the primary fleet was to contain E's and F's. The vote was fourteen to six in favor of a seven-plane fleet; thirteen (a majority of those present) in favor of a two-plane secondary; and tied ten to ten between the C's and the A's as the type of aircraft in the secondary fleet. The group then was tied between our first choice of five four-seat planes and two C's, and five four-seat planes and two A's. Since the C's were considerably less expensive than the A's and the board favored the C's, it seemed nearly certain that they would be purchased, and they were.

To resolve certain administrative difficulties arising out of the meeting, the club sent a followup questionnaire to the members requesting them to rank many of the alternatives. The results of the questionnaire allowed us to reconstruct some of the preferences 
that participants held at the meeting (Figure 3). In addition, we used the results to calibrate the model by comparing conjectured

FIGURE 3

Rankings of Alternatives by Members

Who Atrended the Meeting †

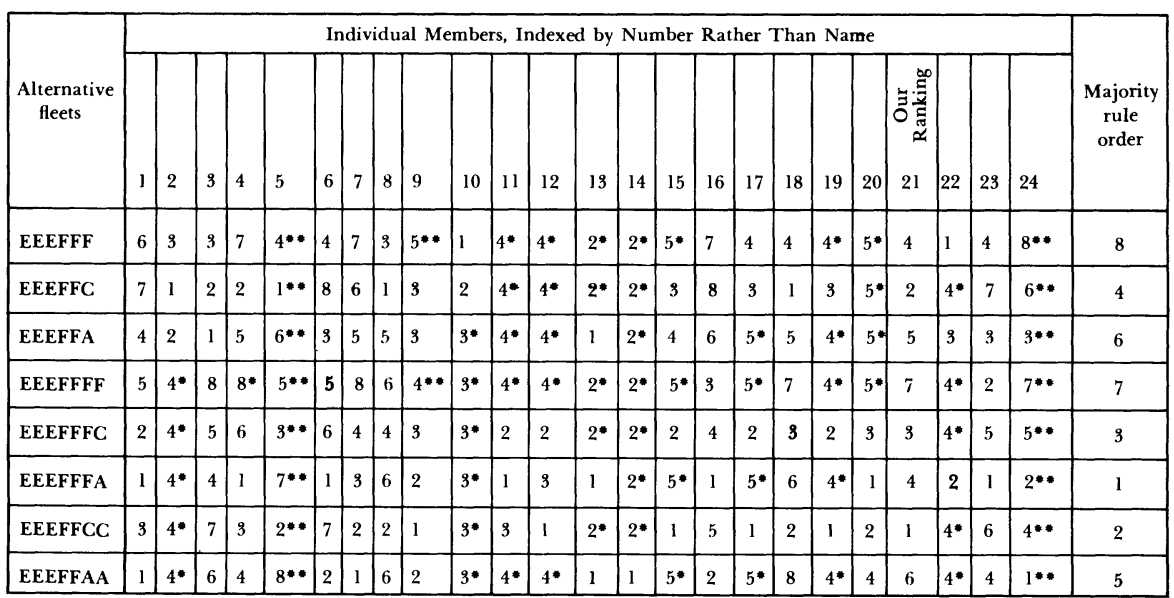

† Preferences are ranked from one (1)-the most preferred alternative-to eight (8) -the least preferred alternative. The group members revealed these preferences in the followup questionnaire to the flying club meeting.

* The individual did not rank this alternative on the questionnaire. We assumed his indifference between this alternative and the other unranked alternatives. We then ranked all the unranked alternatives as least preferred.

** The individual did not rank this alternative on the questionnaire. We estimated his preferences based upon the individual's comments during the meeting and on other occasions. We feel reasonably confident in our accuracy. 
votes on certain items with actual votes recorded at the meeting (Figure 4).

\section{FigURE 4}

Real Vote Totals on Agenda Items and

Our Conjectures About Individual

Voting Patterns $\uparrow$

Question: Do you want a six-plane fleet or a seven-plane fleet?

\begin{tabular}{|c|c|c|c|c|c|c|c|c|c|c|c|c|c|c|c|c|c|c|c|c|c|c|c|c|c|c|}
\hline 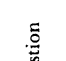 & $\stackrel{\square}{\circ}$ & 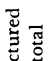 & \multicolumn{24}{|c|}{ Individuals and conjectured individual votes } \\
\hline 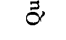 & 巳 ప & 苛 & 1 & 2 & 3 & 4 & 5 & 6 & 7 & 8 & 9 & 10 & 11 & 12 & 13 & 14 & 15 & 16 & 17 & 18 & 19 & 20 & 21 & 22 & 23 & 24 \\
\hline Six & 6 & 6 & & $\mathrm{x}$ & $\mathrm{x}$ & & ti & & & $\mathrm{x}$ & & $\mathrm{x}$ & & & $\cdot$ & & & & & $\mathrm{x}$ & & & & $\mathrm{x}$ & & \\
\hline Seven & 14 & 16 & $\mathrm{x}$ & & & $\mathrm{x}$ & $t \dagger$ & $x$ & $\mathrm{x}$ & & $\mathrm{x}$ & & $\bar{x}$ & $\mathrm{x}$ & $\cdot$ & $\mathrm{x}$ & $\bar{x}$ & $\mathrm{x}$ & $\mathrm{x}$ & & $\mathrm{x}$ & $\mathrm{x}$ & $\mathrm{x}$ & & $\mathrm{x}$ & $\mathrm{x}$ \\
\hline
\end{tabular}

Question: Do you want a one-plane secondary or two-plane secondary?

\begin{tabular}{|c|c|c|c|c|c|c|c|c|c|c|c|c|c|c|c|c|c|c|c|c|c|c|c|c|c|c|}
\hline 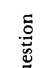 & $\stackrel{\square}{\square}$ & 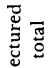 & \multicolumn{24}{|c|}{ Individuals and conjectured individual votes } \\
\hline & $=5$ & $\overline{8}:$ & 1 & 2 & 3 & 4 & 5 & 6 & 7 & 8 & 9 & 10 & 11 & 12 & 13 & 14 & 15 & 16 & 17 & 18 & 19 & 20 & 21 & 22 & 23 & 24 \\
\hline One & $*$ & 9 & $\mathrm{x}$ & * & $\mathrm{x}$ & $\mathrm{x}$ & & $\mathrm{x}$ & & & & * & $\mathrm{x}$ & & * & & & $\mathrm{x}$ & & & & $\mathrm{x}$ & & $\mathrm{x}$ & $\mathbf{x}$ & \\
\hline Two & 13 & 12 & & $\cdot$ & & & $\mathrm{X}$ & & $\mathrm{X}$ & $\mathrm{x}$ & $\mathrm{x}$ & 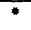 & & $\mathrm{X}$ & $*$ & $\mathrm{X}$ & $\mathrm{X}$ & & $\mathrm{X}$ & $\mathrm{x}$ & $\mathrm{X}$ & & $\mathrm{x}$ & & & $\mathrm{X}$ \\
\hline
\end{tabular}

Question: Do you want C-210's or A-36's as the secondary fleet?

\begin{tabular}{|c|c|c|c|c|c|c|c|c|c|c|c|c|c|c|c|c|c|c|c|c|c|c|c|c|c|c|}
\hline$\stackrel{\tilde{g}}{\tilde{H}}$ & $\stackrel{\square}{\stackrel{0}{\circ}}$ & 总 & \multicolumn{24}{|c|}{ Individuals and conjectured individual votes } \\
\hline & & 8 & 1 & 2 & 3 & 4 & 5 & 6 & 7 & 8 & 9 & 10 & 11 & 12 & 13 & 14 & 15 & 16 & 17 & 18 & 19 & 20 & 21 & 22 & 23 & 24 \\
\hline C-210's & 10 & 11 & & - & & $\mathrm{x}$ & $* *$ & & & $\mathbf{x}$ & $\mathrm{x}$ & * & $\mathbf{x}$ & $\mathrm{x}$ & & & $\mathrm{x}$ & & $\mathrm{x}$ & $\mathrm{x}$ & $\mathrm{x}$ & $\mathrm{x}$ & $\mathbf{x}$ & $\bullet$ & & \\
\hline A-36's & 10 & 9 & $\mathrm{x}$ & * & $\mathrm{x}$ & & $* *$ & $\mathrm{x}$ & $\mathrm{x}$ & & & $*$ & & & $\mathrm{X}$ & $\mathbf{X}$ & & $\mathbf{X}$ & & & & & & * & $\bar{x}$ & $\mathrm{X}$ \\
\hline
\end{tabular}

$\dagger$ The conjectured votes (marked by $\mathrm{x}$ ) are based upon the individual's most preferred alternative in the followup questionnaire. See Figure 3.

$\dagger+$ The individual did not vote on this question.

* Our criteria yield an ambiguous result. The conjectured vote total counts the individual as abstaining.

** The real vote count was unavailable.

*** The individual left the meeting. The conjectured vote total counts him as voting for the C-210's. 
Our approach seemed to have worked. Several things happened that tended to reinforce this impression. The chairman of the group strongly favored A's and seemed uninhibited in his efforts to use the chair to change the agenda in ways that would influence the outcome to his advantage.

Here are some of the alternative agendas he attempted to use: As soon as the introductory remarks were over and before any of the items on our agenda were on the floor, he called for a vote on, "Do we want an all-Bonanza [E, F, or A] fleet?" According to our theory, this motion unquestionably would have passed and regardless of the later items, the club would have voted for at least one A and probably two. His motion was ruled out of order because the agenda committee had adopted our agenda. Then after the primary fleet was selected, but before the size of the fleet was voted upon, he asked: "Do we want A's or C's as a secondary fleet?" Again, checking how the vote would have gone according to our theory we find that the group would have chosen an $\mathrm{A}$ at this stage. The ultimate choice would have been a seven-plane fleet with one A, regardless of the wording of the later items. But he was ruled out of order. Then after we determined the fleet size but before the number of planes in the secondary fleet was decided, he asked: "Do we want at least one A?" The answer to this question would have been "yes" by a vote of thirteen to nine. We called his attention to the fact that he had again deviated from the agenda and that his motion could not be taken as a substitute. Members of the meeting supported all of our procedural objections.

Another indication that the agenda was influential is that the Condorcet winner ${ }^{15}$ (the seven-plane fleet with an A secondary) was beaten by a careful grouping of alternatives against it.

\section{VI. “LABORATORY” EXPERIMENTS}

Although we believed that we had influenced the outcome of the flying club meeting, it represented only one uncontrolled "confirmation" of our theory. We first sought to confirm our interpretation of the flying club episode by conducting a series of more controlled, but pro tanto less realistic, experiments using a highly refined and abstract analogue to the procedures used at the flying

15 A Condorcet winner is an alternative that beats all other alternatives in binary (pairwise) comparisons under majority rule. 
club meeting. ${ }^{16}$ We sought to induce preferences in our subjects by presenting them with a schedule of monetary payoffs that each would receive in the event that the group adopted one of the alternatives presented to it. Payoffs differed among individuals and varied for any individual depending on which alternative the group adopted. In short, to the extent that any subject preferred getting a larger payoff to a smaller one, he would prefer some alternatives to others. We assumed for our experiments that this technique produced a group of subjects who had different experimentergenerated preferences among the alternatives facing the group. ${ }^{17}$

In broadest terms, our experimental design was to take groups of subjects with identical preference configurations and, using identical procedures, have each group make a choice according to an agenda (different for each experiment) we had prepared. Our task was to predict each outcome based on the preferences of the individuals in the group and our agenda partitions. If we could predict and reach different outcomes from groups with identical payoff schedules (preferences) by varying only the agenda, we could claim, at least for the controlled situation, that the agenda systematically influenced the group choice.

We conducted pilot experiments (Appendix) that modeled closely the flying club meeting. Although there were some technical defects in the experimental procedures we used, these experiments seemed to confirm the importance of the agenda in reaching the flying club result. We then further refined our model, cleaned up our experimental procedures, and conducted another series of experiments.

The laboratory experiments involved college students who were promised an opportunity to make well over the prevailing hourly wage earned by their classmates. Each student volunteer was told that the experiments related to certain logistical and technical problems of group decisionmaking. ${ }^{18}$ Before each experiment, the instructions were read by the experimenter who did not know at

16 For a more detailed report of these results, see Plott \& Levine, supra note 7, at - - .

17 For a further discussion of the theory underlying this technique, see Smith, Experimental Economics: Induced Value Theory, 66 Am. Econ. Rev. Papers \& Proceedings 274 (1976).

18 In addition, the students were told that they would be subject to no harm or embarrassment and that the experiment did not involve psychological or personal variables. 
the time which alternative the agenda was designed to produce. ${ }^{19}$ A student acting as chairman for these experiments conducted each meeting according to a prepared set of instructions. The chairman did not know the purpose of the experiments, nor that we had any expectations about which alternative the group would select.

In each experiment, the participants were encouraged to discuss their relative preferences but were not permitted to reveal quantitative information about payoffs. After the vote on each item, the group considered the next item on the agenda. On two or three occasions someone asked if items could be changed. This was not allowed. We suspect that certain types of straw votes in effect change the agenda and may affect outcomes. Although we never prohibited a straw vote, we were prepared to rule one out of order if it were put in the form of a substitute agenda-for example, "If it comes down to box A versus box B later, how many will go for A?" We did allow one straw vote in this series, and we think it did affect the outcome. ${ }^{20}$ When the meeting was over, all subjects were paid in cash the amount dictated by their payoff sheet and the alternative chosen by the group.

The payoff schedules and majority-rule rankings are listed in Figure 5. Alternative 1 beats all others in any binary contest (it is the Condorcet winner), and alternative 5 is beaten (unanimously) by any of the others in a binary contest. The other three alternatives are involved in a cycle. ${ }^{21}$ Although it would have been more dramatic to avoid this cycle, we were unable to find a noncyclic example for which a "probability one agenda" ${ }^{22}$ could be constructed according to our model for each feasible item, given the probabilities measured from pilot experiments. Our experience with pilot experiments had taught us not to take chances, so we

\footnotetext{
19 The only person present during the experiment who knew which alternative was theoretically supposed to occur was our graduate research assistant. He was introduced as the recording secretary and spoke only in connection with counting votes.

20 See Figure 6, experiment 2 \& alternative specification, experiment 2.

21 A cycle is a condition under which a group (for example, individuals $A, B$, and $C$ ) using a particular decision rule (most commonly discussed for majority rule) chooses alternatives $\mathrm{X}, \mathrm{Y}$, and $\mathrm{Z}$ as follows. $A$ prefers $\mathrm{X}$ to $\mathrm{Y}$, and $\mathrm{Y}$ to $\mathrm{Z}$. $B$ prefers $\mathrm{Y}$ to $\mathrm{Z}$, and $\mathrm{Z}$ to $\mathrm{X}$. $C$ prefers $\mathrm{Z}$ to $\mathrm{X}$, and $\mathrm{X}$ to $\mathrm{Y}$. By majority rule, the group would choose $\mathrm{X}$ over $\mathrm{Y}$, $\mathrm{Y}$ over $\mathrm{Z}$, and $\mathrm{Z}$ over $\mathrm{X}$. See Figure 5 .

22 A "probability one agenda" is an agenda for which our model predicts with certainty that a particular item will be chosen.
} 
Figure 5

PAyofFs IN Dollars

\begin{tabular}{|c|c|c|c|c|c|}
\hline \multirow{2}{*}{ PERSON } & \multicolumn{5}{|c|}{ ALTERNATIVE } \\
\hline & 1 & 2 & 3 & 4 & 5 \\
\hline 1 & 6.00 & 7.00 & 5.00 & 8.00 & 0.50 \\
\hline 2 & 6.00 & 7.00 & 5.00 & 8.00 & 0.50 \\
\hline 3 & 6.00 & 7.00 & 5.00 & 8.00 & 0.50 \\
\hline 4 & 6.00 & 7.00 & 5.00 & 8.00 & 0.50 \\
\hline 5 & 6.00 & 7.00 & 5.00 & 8.00 & 0.50 \\
\hline 6 & 6.00 & 7.00 & 5.00 & 8.00 & 0.50 \\
\hline 7 & 7.50 & 7.75 & 6.75 & 5.75 & 0.25 \\
\hline 8 & 7.50 & 7.75 & 6.75 & 5.75 & 0.25 \\
\hline 9 & 7.50 & 7.75 & 6.75 & 5.75 & 0.25 \\
\hline 10 & 7.50 & 7.75 & 6.75 & 5.75 & 0.25 \\
\hline 11 & 7.50 & 7.00 & 6.00 & 8.00 & 0.50 \\
\hline 12 & 8.00 & 7.50 & 7.00 & 6.00 & 0.50 \\
\hline 13 & 8.00 & 7.50 & 7.00 & 6.00 & 0.50 \\
\hline 14 & 8.00 & 7.50 & 7.00 & 6.00 & 0.50 \\
\hline 15 & 7.00 & 5.50 & 7.50 & 6.50 & 0.25 \\
\hline 16 & 7.00 & 5.50 & 7.50 & 6.50 & 0.25 \\
\hline 17 & 7.00 & 5.50 & 7.50 & 6.50 & 0.25 \\
\hline 18 & 7.00 & 5.50 & 7.50 & 6.50 & 0.25 \\
\hline 19 & 7.00 & 5.50 & 7.50 & 6.50 & 0.25 \\
\hline 20 & 7.00 & 5.50 & 7.50 & 6.50 & 0.25 \\
\hline 21 & 7.00 & 5.50 & 7.50 & 6.50 & 0.25 \\
\hline $\begin{array}{l}\text { Majority rule } \\
\text { relation }\end{array}$ & $\begin{array}{c}1 \\
\text { first }\end{array}$ & & cycle & & $\begin{array}{c}-5 \\
\text { last }\end{array}$ \\
\hline
\end{tabular}


chose the cyclical ordering to get a better probability for the result we wanted. In each of the four experimental agendas, we used different letter labels (A-E) to represent the set of five alternatives. ${ }^{23}$

The results of these experiments are in Figure 6. Experiments 1, 3 , and 4, which were designed to get alternatives 3, 2, and 1 respectively, performed exactly as predicted. Each resulted in the choice of alternatives for which the agenda was designed. The agenda for experiment 2 was designed for alternative 4 , but the group chose alternative 1 . This resulted because a straw vote revealed the fact that alternative 5 (labeled $\mathrm{D}$ in this experiment) was least preferred by all individuals.

Under the circumstances, there is some ambiguity about exactly what we observed. Did we call three out of four shots or did we call four out of four? Which event occurred depends upon whether or not we are allowed the luxury of the ex post prediction. The straw vote, we claim, effectively changed the agenda to the one in the figure labeled "Alternative Specification: Experiment 2." For this alternate agenda, the model predicts letter $\mathrm{E}$, the one actually chosen, with a .93 probability. There are two possible competing interpretations. The first is what we claim we observed-that in all four cases the results were consistent with the theory. This requires that we assert that the actual agenda of experiment 2 was the alternative specification resulting from the straw vote, rather than the one we constructed. The second interpretation would reject our explanation of experiment 2. One could argue that at best we exhibited an ability to predict only three out of four outcomes.

We have calculated elsewhere ${ }^{24}$ that it is very unlikely that our result could have been achieved independently of the influence of the agenda. We conclude from these experiments that there are at least some circumstances under which the agenda influences the outcome in a systematic, predictable way.

23 For example, the agenda for experiment 1 labeled alternatives 1 through 5 as E, C, B, $A$, and $\mathrm{D}$ respectively. See Figure 6.

24 Plott \& Levine, supra note 7 , at - - - 
FiguRE 6

Results of LABORATORY EXPERIMENTS

Experiment 1

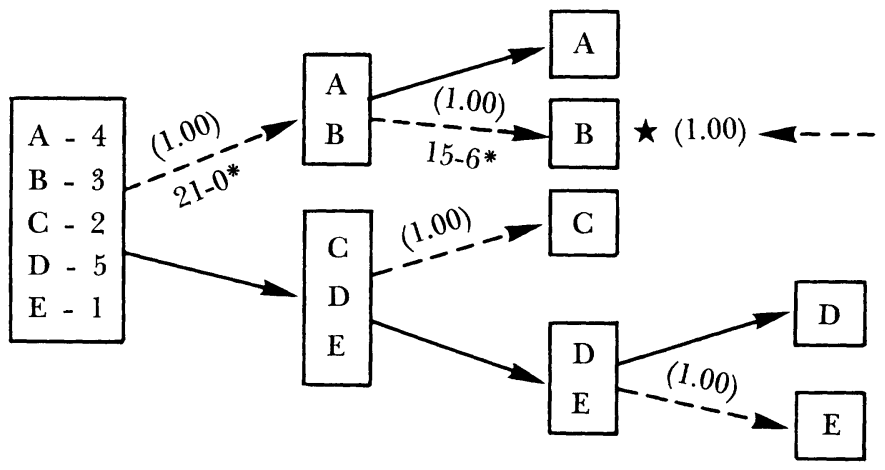

Experiment 2

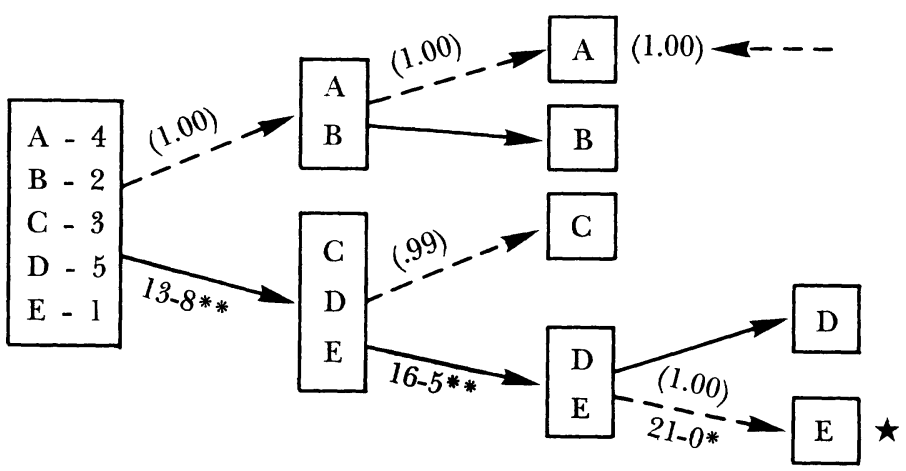

Alternative Specification: Experiment 2

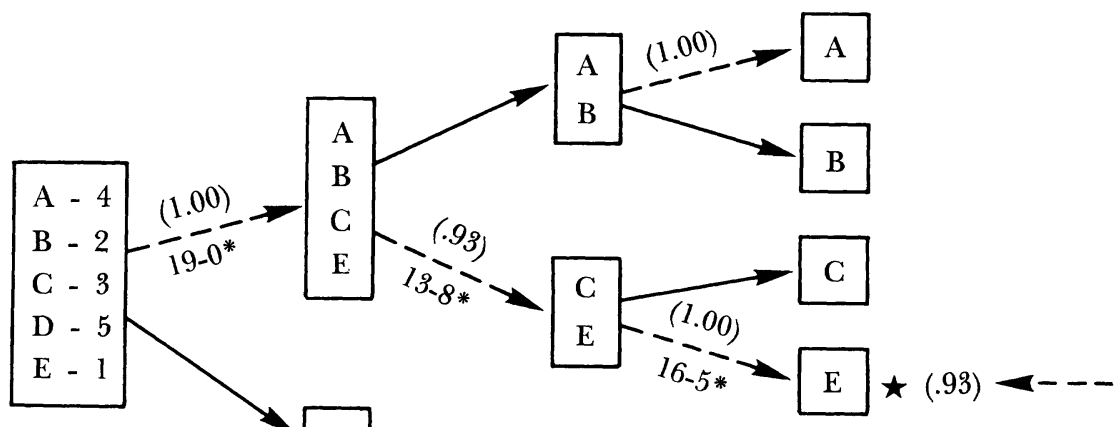




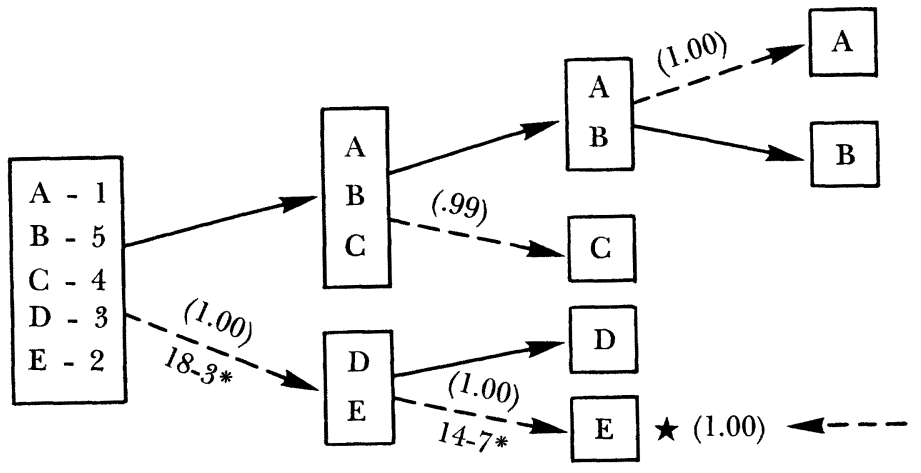

\section{Experiment 4}

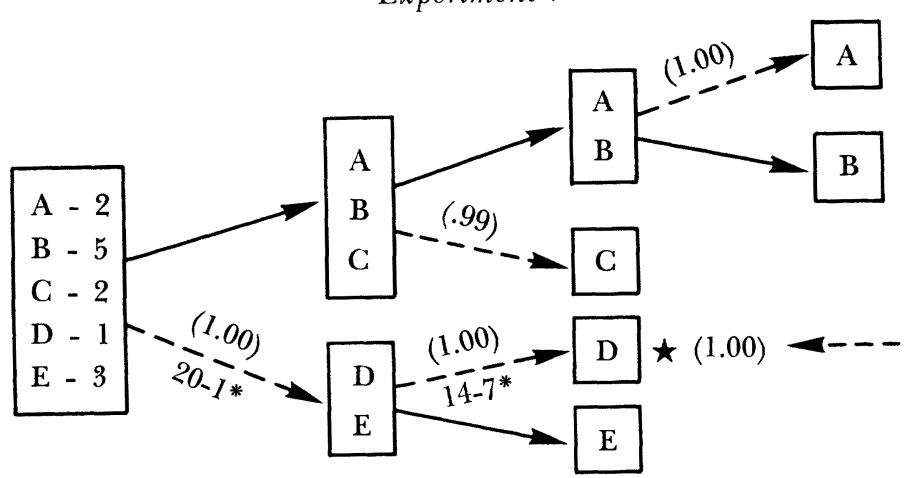

KEY

$(\mathrm{x})$ means that $x$ is the "strength" of the set of alternatives over the competing set of alternatives as determined by the model.

$(\mathrm{x})$ - means that $\mathrm{x}$ is the "strength" of the agenda in getting this alternative. Each agenda was designed to get the alternative so marked.

$x-y^{*} \quad$ means that at this stage the vote went "our way" by a vote of $x$ to $y$.

$x-y *$ means that at this stage we "lost" by a vote of $x$ to $y$. indicates the actual final choice made by the group. 


\section{Implications AND Applications}

What are the possible implications of what we learned and of what we think one might learn to do? If there are many reai-world analogues to the processes we have modeled, our research raises both ethical and practical issues. Processes seem to be accepted as legitimate in part because they are thought to allow decisions to be based impartially on the substantive preferences of the participants toward the alternatives presented. Although "intrinsic" qualities of procedures can probably be appraised normatively without reference to subject matter, it is ordinarily a serious objection to a candidate process that it systematically and predictably can be made to select certain outcomes even though other outcomes are thought to command "more" support. Indeed, this sort of complaint has been important in past efforts to reform the congressional committee system..$^{25}$

Thus, procedural manipulations that overtly dictate decisions are often regarded as ethically suspect. Enhancing anyone's ability to manipulate decisions reliably and consistently in this way may seem to subvert the goal of reaching decisions that reflect the "preference of the group." But the social choice literature suggests that groups may have no preferences that are independent of the method used for aggregating individual preferences. ${ }^{26}$ For any given set of individual preferences, groups can reach a variety of outcomes by majority processes that reflect the views of the individual members with respect to the alternatives presented..$^{27}$ If there is no outcome that the group "wants" independently of the procedure used to reach the decision, all one can do is choose an acceptable agenda that dictates the final result. The notion of "subversion" becomes empty if there is no single true reflection of a group's preferences, only a set of possible outcomes that depend on the agenda. In addition, procedural deftness may be no more

25 The House Rules Committee's manipulation of the order and timing in which bills are voted upon and its use of the "closed rule" prohibiting floor amendments are examples of agenda influence. These were a major source of discontent with House procedure, some of which was alleviated by the reforms of 1961. See J. Robinson, The House Rules Committee 43-46 (1963); Cummings \& Peabody, The Decision to Enlarge the Committee on Rules: An Analysis of the 1961 Vote, in New Perspectives on the House of Representatives 253 (R. Peabody \& N. Polsby eds. 1969).

26 See references cited notes 2-3 supra.

27 See R.D. Black, supra note 4; R. Farquharson, Theory of Voting (1969). 
nor less an acceptable skill than are rhetorical gifts, a feel for group psychodynamics, or charisma. Perhaps any initial ethical reactions to overt examples of nonneutral processes rest on mistaken notions of the alternatives available to us. Further explorations of process (agenda) acceptability independent of result ${ }^{28}$ might point toward principled resolutions of these problems.

As a practical matter, the thrust of our research suggests that processes commonly used to reach important decisions may be subject to a degree of agenda influence ranging from mild to surprising. This influence may, of course, be intentional where the possibilities are perceived by those having a stake in the outcome. But they may as well be accidental, an artifact of process features adopted with the most outcome-neutral intentions. While it is clear that further research would be useful in identifying and specifying agenda influence on commonly used processes, it is also clear that the usefulness of doing so would be greatly enhanced if what makes processes "fair" were well enough understood to allow intelligent discussion of the tradeoff between desirable process features such as certainty, efficiency, participatory opportunity, democracy, and the like on one hand, and their outcome influences on the other.

In addition, our research suggests that there are situations (e.g., the flying club decision) where some people (e.g., the flying club chairman) are able to intuit which procedural decisions will work to their advantage and attempt to use them. The research also suggests that two determined observers armed with a computer, graduate students, and iron control over the agenda can do as well. Perhaps agenda factors influencing the outcomes of group decisions should be made more generally known, and other processes susceptible to these influences should be identified. Such publicity might be an important step toward a kind of equality of access to procedural influence that has not previously been considered possible or relevant.

What real-world decision processes might be subject to the influences we have explored? It is difficult to tell. Our results were generated by a relatively simple model whose exact analogue is difficult, although not impossible, to find in real-world institutions.

28 See Michelman, Formal and Associational Aims in Procedural Due Process, in Nomos XVIII: Due Process - (J. Pennock \& J. Chapman eds. 1977). 
And even real-world institutions that seem prima facie to be fairly similar to the processes with which we experimented almost always possess additional features whose significance for our model is ambiguous. But a few are quite close to the processes we explored, and others seem to have characteristics that might allow them to be modeled by modified or extended versions of our theory.

Strictly speaking, we have modeled only relatively large groups whose decision rule is majority rule, where preference revelation is relatively ineffective except through the voting process (although the flying club debate allowed considerable preference revelation), where the order and grouping of alternatives is tightly controlled by means of an agenda that is not itself generated as part of the voting process, and where opportunities to reconsider decisions once made are limited. The most obvious analogues to such processes are certain legislative proceedings. The United States House of Representatives proceeding under a "closed rule" (which allows no amendments except those authorized by the committee and may limit or eliminate debate $)^{29}$ is operating within the perimeters of our model. We would expect such proceedings to be profoundly affected by the order in which amendments are presented and by the order in which the legislation in question is taken up relative to other matters to be considered by the House. This "agenda" is provided by the appropriate committee and by the House leadership, which controls the calendar. Even under more relaxed procedures, such as open amendments, the order in which amendments are presented and the difficulty of reconsidering may produce agenda influence. And leadership decisions as to whether a bill is considered before or after other bills whose fate might affect members' judgments about the bill in question clearly involve the agenda phenomenon we have articulated. In the same way, the Congress's perennial reluctance to accede to the equally perennial proposal that the President be given the item veto represents congressional determination to control the manner in which issues are partitioned for presentation to the President by offering bills that must be signed or vetoed (voted on) as a package.

These affinities to the phenomenon we have investigated may add further suspicion to already doubtful notions of legislative

29 For an anecdotal account of the impact of such a procedure, $\rightarrow$ Graetz, Reflections on the Tax Legislative Process: Prelude to Reform, 58 VA. L. REv. 1389, 1435-40 (1972). 
intent and statutory purpose. These concepts have often been thought to be suspect on grounds of general murkiness or confusion, and perhaps are not often taken seriously as importing a notion of group intent to the legislature, but they may now be seen to have still another defect. It may seem less acceptable even than it does now to ascribe a "dominant" purpose to a statute or an "intent" to a legislature when the issue is not only why differing legislators voted for a given bill, but whether that bill or some quite different bill would have commanded a majority had minor modifications been made to the legislative agenda.

Another obvious application of our model is to electoral institutions already scrutinized in other terms in the political science literature. ${ }^{30}$ It should be obvious to the reader by now that the sequence of primary elections, followed by runoffs, followed by a general election represents a series of partitions of candidates which yields readily to our analysis, and that different candidates might be elected if either the primary or the runoff were eliminated. It is a commonplace by now that certain candidates who could probably be elected cannot get nominated when a primary pits them against candidates more palatable to their own party but less palatable to the electorate as a whole. This commonplace is equally true of political conventions.

Moreover, conventions offer additional opportunities for agenda influence. The 1976 efforts of Governor Reagan's forces to require Republican presidential candidates to announce their vice-presidential choices before the balloting for presidential candidates took place were obviously grounded in expectations of agenda influence. ${ }^{31}$ The Ford proponents clearly felt more confident in a twostage process first pitting all alternatives with an " $F$ " against all those with an "R", while the Reagan supporters felt they had a better chance in a one-stage process in which "Fx" was pitted against "Ry" (where " $x$ " and "y" denote vice-presidential choices). Which of those procedures was "fairer"? Was it the one that gave all delegates the opportunity to register separately their preferences for presidential candidates without the "extraneous" vice-presidential matter intruding, but concealed possibly disagreeable

30 See, e.g., W. Riker \& P. Ordeshook, An Introduction to Positive Political Theory (1973)

31 See New York Times, Aug. 11, 1976, \$ 1, at 1, col. 8; id., Aug. 12, 1976, at 1, col. 7. 
choices of runningmates from the potentially disaffected? Or was it the one that would have allowed delegates an opportunity to vote for the final ticket as a package, but given them no opportunity to express their preferences separately on the most important issue before them? Was either candidate the "choice" of the Republican Convention?

Other legal decision processes share important features-majority rule and the need to break up a complex matter into subissueswith our model, but show significant variations in other respects that reduce our ability to predict the degree of agenda influence. Perhaps the most important of these processes are the deliberations of administrative commissions and appellate courts. The internal decision processes of both these institutions are not well known (although "sunshine laws" may make it possible to gain some insight into the deliberative processes of administrative commissions), but both display the potential for agenda influence. In the case of the administrative commission, a hearing examiner or an administrative law judge may break down the proceeding into a series of subissues that the commission may consider in its deliberations. An example ${ }^{32}$ is the process used in Civil Aeronautics Board route proceedings in which the "need" for service and the exact service pattern to be awarded are defined as issues separate from carrier selection and service restrictions, but such decision procedures are common wherever administrative agency issues are very complex. If the commission votes on these subissues seriatim, there is a strong possibility of agenda influence.

Sometimes an agency forces itself into voting seriatim. For example, the most important rate case in the CAB's history, the Domestic Passenger Fare Investigation, was divided in a series of organizing orders into subissues or "phases," ${ }^{33}$ such as discount fares, fare level, rate of return, and fare structure, which were voted on and decided separately. Such a procedure seems very likely to yield a different result from that which would have been reached if the Board had decided the case in its entirety in one decision. This is clearly agenda influence, but accepting such influence may

32. For a discussion of the CAB's step-by-step procedure, see Delta Airlines v. CAB, 442 F.2d 730, 732-33 (D.C. Cir. 1970).

33 See Domestic Passenger-Fare Investigation, 53 C.A.B. 842 (1970). 
be the only way to cope with a very complex matter in a reasonable amount of time.

Indeed, for most complex decisions made by voting groups, some subdivision seems to be necessary, and the very complexity of the matter at hand may limit reconsideration of subissues once decided. As one example, although little is known about the internal deliberations of appellate courts, ${ }^{34}$ a procedure at decision conferences in which issues in complicated cases are taken up in series and voted upon could be subject to the possibility of agenda influence. $^{35}$ The circulation of opinions among judges or justices undoubtedly would mitigate this possibility, but only to the extent that the matter could be revoted upon or the opinion greatly changed within the confines of the original vote. If the case were complex enough, however, as in the case of the administrative commission, it is difficult to see how it could be decided without some sort of seriatim voting on subissues.

Indeed, even a case taken as a whole may represent only one element in a decision process defined by a series of cases presented, for example, to an appellate court for review. In this situation, which can occur as a result of a deliberate effort to establish a principle through a coordinated line of cases or which can occur "naturally" as unconnected cases come up for decision, the practice of stare decisis (limiting the amount of reconsideration that can be given to a recently established decision) combines with a temporal sequence of cases requiring voting decisions by the appellate court to produce an agenda-like situation. Our model suggests that different bodies of law may well be established when cases are presented in one order than when they are presented in another. Clearly, effects of this type are considered intuitively or explicitly when an organization is trying to determine the "right" case to appeal to establish a principle, or is mapping a strategy that in-

34 A few efforts to describe judicial decisionmaking exist, but the tradition of secrecy surrounding the process limits observers to speculation and deduction based on a few known facts such as assignments of opinions by chief judges, correlations in voting among members of the court, judges' political backgrounds, and even the shape of the table used for decision conferences. See, e.g., W. Murphy, Elements of Judicial Strategy 37.90 (1964); D. Rohide \& H. Spaeth, Supreme Court Decision Making 134-92 (1976).

35 One model of how this could occur makes creative use of Black's important early work on committees, see R.D. BLACK, supra note 4, to demonstrate how a Chief Justice could use the agenda at a decision conference to favor one element of a majority-rule cycle and thus ensure the adoption of his preferred outcome. W. MURPHY, supra note 34, at 86-87. 
volves successive challenges to a general principle in order to erode it. And in some sense, the general march of precedent in related areas of law probably exerts an agenda influence over much appellate decisionmaking. ${ }^{36}$

Appellate courts, of course, are not without awareness of the possibility (at least within a term or several adjacent terms) of agenda influence. Certiorari may be granted or denied because of "ripeness" considerations, and those considerations may include the effects of deciding the instant case on possible related cases that might otherwise precede it. And the Supreme Court, through its power to limit grants of certiorari to particular issues in a case, ${ }^{37}$ may itself consciously attempt to neutralize or accentuate agenda influence.

Another very interesting potential area for the operation of agenda influence arises in connection with jury deliberations. Although the deliberative process is only little known, ${ }^{38}$ we might assume that in complex cases it proceeds in stages. At a minimum, liability may be discussed separately from damages in civil actions, but one can imagine much more complicated considerations of multicount complaints with various affirmative defenses, crossactions, and multiple damage claims. The judge's charge to the jury may itself operate as an agenda and may influence the outcome. Or, an internally generated agenda agreed upon before discussion and voting on the merits may control the jury's deliberations. With a general verdict, some of these influences may be

36 For an interesting brief discussion of the possibility of agenda influence in the sequencing and scope of cases presented for judicial decision, see D. Horowitz, THE Courts and Social Policy 39-41 (1977). Horowitz emphasizes what he characterizes as the usual lack of participant control over agenda influence, but also recognizes situations in which a litigating organization can attempt to use agenda influence. For examples of situations where litigants attempted to use agenda influence, see M. Meltsner, Crufl and Unusual 60-185 (1973); L. Miller, The Petitioners $344-45$ (1966); C. Vose, Caucasians ONIY 50-73 (1959).

37 See Bice, The Limited Grant of Certiorari and the Justification of Judicial Review, 1975 Wis. L. Rev. 343, 346-62.

38 The authors were unable to discover any detailed examination of the jury deliberation process. Kalven and Zeisel's important and extended study of jury behavior is skeptical of the value of information relating to the processes used by deliberating juries perhaps because its authors see deliberation as functioning principally to change or express preferences, rather than as a method of combining individual preferences (fixed or not) to yield a result. H. Kalvif \& H. Zfisfi, The American Jury 486-89 (1971). In consequence, their expressed interest in further exploration of deliberative phenomena focuses almost entirely upon the effect of deliberation on the preferences of individual jurors. $I d$. at 489 . 
mitigated by the need to secure overall agreement, but even here it is possible to imagine that a jury which took up damage questions before liability questions might reach a quite different result from that which it would reach if it took up liability first. ${ }^{39}$ In the same way, a jury might reach different verdicts on a multiple count criminal indictment depending upon the order in which the counts were taken up.

We investigated a majority rule model with known procedures. Where the jurisdiction allows the jury to reach less-than-unanimous verdicts (as in many state courts), deliberations according to an agenda would be subject to predictions generated by our model. If we do not know the procedure (agenda) used by the jury, we could not be certain of agenda effects, but as long as some ordering is adhered to, such effects are possible. Strictly speaking, we cannot say anything about the effects on unanimous verdicts of issue partitioning and of the order of deliberations, but our theory and its results suggest that this might be a fruitful line of inquiry, perhaps through laboratory experimentation.

More important, perhaps, is the bearing our findings have on at least two recently popular jury reform ideas, less-than-unanimous verdicts and special verdicts. Taken together, these convert the jury deliberating process into one that precisely conforms to our model and that we predict would be subject to agenda influence. The special verdict, at least in its most commonly proposed form, ${ }^{40}$ is an agenda for the jury. It divides an overall issue (liability or guilt) into a series of subissues to be taken up seriatim. If a jury were to vote on these by majority rule ${ }^{41}$ without deviating from the order ${ }^{42}$ in which the issues were posed by the judge, it would

39) At least one study supports this speculation. In an examination of negligence cases, the study found that defendants won $42 \%$ of the time when the jury decided the liability and damage issues simultaneously, but that defendants won $79 \%$ of the time when the jury decided only the liability issue (with damages tried separately if liability was found). Rosenberg, Court Congestion: Status, Causes, and Proposed Remedies in THE CourTs, THE Public, and The Law Explosion 29, 48 (H. Jones ed. 1965).

40 See, e.g., Lee, Forms of Interrogatories, 38 F.R.D. 207, 212-14, 217-19 (1965).

41 If the jury were to use some other less-than-unanimous voting rule, the process would still be within the confines of our model. Changes in the voting rule theoretically alter the strength of one alternative against another and the strength of any given agenda. Obviously, as the voting rule approaches unanimity, opportunities for influence decline, but they do not disappear.

42 Of course, as occurred in our laboratory experiments, a jury that took straw votes on issues "out of turn" would be creating its own agenda and might alter the influence of the special verdict agenda. 
be using a process identical to the one we investigated. If, in addition, jury profile analysis or other sophisticated methods were employed by counsel to construct an approximation of the individual preferences of the jury members, counsel would be in a position to conduct a variant of our experiments. By proposing special verdict questions in an innocent-appearing order for adoption by the trial judge, counsel might well be able to influence the verdict in a predictable way. And in light of our experiments, how would a trial judge choose between two ostensibly neutral sets of jury questions proposed by opposing counsel when all concerned know that the sequence selected is likely to influence the verdict? This possibility alone suggests a feature of less-than-unanimous jury voting, at least where combined with special verdicts, that should be taken into account in deciding whether to adopt these reforms.

Finally, there is a whole range of lawyer-dominated decision processes that seem to be sensitive to partitioning and ordering of issues but which do not at first examination conform to the conditions of our model. Collective bargaining and settlement negotiations may be illuminated by our theory, if only because even groups requiring unanimity (which may be one way to model a two-participant decision) may be affected by partitioning and ordering. One might use an agenda in ways analogous to, but not modeled by, our theory to affect outcomes. For example, postponing bargaining on difficult issues may be a way of showing the parties how much agreement on earlier issues would be lost if they cannot agree on the harder, later ones, and thus might salvage a negotiation that would break down if conducted in reverse order. And pretrial conferences may be thought of as ways to set the agenda for jury deliberations or, in a judge-tried case, an agenda for majority-rule determination with the judge casting the deciding vote on each issue. The pretrial conference may be used as well by counsel to keep in or throw out issues that might be especially likely to create the highly divided, multi-issue environment in which agenda influence is most likely to exist. Administrative law counsel, and in particular the administrative law judge or hearing examiner, may have even greater power of this kind by setting issues in prehearing conferences that will ultimately be decided by a majority-rule commission.

Our inquiry may help to focus attention on some general questions about the legitimacy of group decisions reached by majority 
rule. For example, if the same group using the same voting rule can reach different outcomes by using different agendas, are there independent criteria by which we can decide which of the feasible agendas and outcomes is more legitimate? One excruciatingly difficult plan of exploration leads away from defining acceptable outcomes by reference to individual preferences working through "fair" procedures and back toward defining acceptable outcomes by reference to "external" criteria. One might approach Rawls' 43 "difference principle" as an effort to specify which of many outcomes available to a group is best by an appeal to intrinsic, rather than process-related, justification. Whether or not one regards Rawls' particular effort as successful, the value of such a criterion is magnified by our inability to identify neutral (and hence "fair") processes for resolving intragroup conflict. And if the weaknesses in Rawls' heroic effort make us insecure about the prospects of a search for intrinsic justice, perhaps some development of Rawls' own procedure, namely the "original position" with its "veil of ignorance" (used in his work to "find" the "difference principle"), might be a starting point for explorations designed to legitimate processes by examining them for acceptability in a hypothesized state of ignorance. These explorations might help us to address such questions as, "Should more or less deference be paid to Condorcet winners ${ }^{44}$ as a result of considering the implications of agenda influence?"

The difficulty of satisfactorily dealing with problems of this sort may shed some light on the analytic appeal of such apparently unrealistic decision criteria as those based on the Pareto Principle. If majoritarian procedures entail paradoxes and difficult choices, the analyst can resort to a kind of unanimity, accepting severe limits on the range of choices that can be made in return for the comfortable security of recommending only choices that leave no one worse off.

On the other hand, perhaps we presume too much in raising such issues on the basis of a few observations about agenda influence. Perhaps once the influence of the agenda is known to the participants in a group decision, it will cease to affect them. If correct, this is an argument at least for generating and disseminat-

43 J. Rawls, A Theory of Justice (1971).

44 See note 15 supra. 
ing results such as ours. But we suspect that many of the outcomes reached in our experiments would have been reached by a group that was familiar with the principles involved, once any given agenda had been adopted. Should further work confirm our suspicions, we can only speculate about the difficulties knowledgeable groups may have in solving the infinite regress problem of determining an agenda for deciding on an agenda. One result might be an increased resort to stochastic decision techniques or to procedures in which participants take turns at being dictator.

Once the influence of the agenda is generally understood, we can use the knowledge to gain insights into the way complex group processes actually function and to refine our attitudes toward them. Our untested suspicion is that institutions frequently influence groups to take positions as a result of some inadvertent procedural decision. Pursuing this line of inquiry may enable us to recognize the limitations of the processes society uses to make group decisions and to "design around" them to the extent possible. As a specific example, our earlier discussion might be used to reassess the longstanding interest in special verdicts. This interest might be significantly dampened if it were known that a series of special interrogatories may be much more susceptible to conscious manipulation than an unstructured general verdict. The same might be true for proposals to accept less-than-unanimous verdicts in federal courts. In addition, states now using both lessthan-unanimous and special verdicts might wish to reevaluate the practice. And inquiries into such arcane matters as the deliberative procedure of juries and the decisionmaking processes of appellate tribunals and voting-type administrative agencies might be of considerably more interest than at present if the information gained points to the susceptibility of those institutions to conscious or unconscious procedural influences.

Potential applications of this sort emphasize the importance of further investigation. Our laboratory experiments were simple; the world is complex. Outside the laboratory, groups debate alternatives that lend themselves to argument and discussion. Argument and discussion frequently involve new information and appeals to general principles that may create conflicting preferences in individual participants. The personalities of individual participants may exert positive or negative influences on the votes of other members of the group. Leadership, charisma, and feelings of 
deference may give the preferences of one individual more weight in the process than the preferences of others. Previous group history may influence events. Agenda items may be recharacterized or perceived differently by the introduction into the discussion of facts or projections. Finally, feelings of "fairness," either in the form of attachment to certain processes or of limits to the effects of outcomes on other individuals in the group, may exert important influences on decisions. The experimental environment may have suppressed many of these effects and, even if the flying club environment did not, the club meeting was after all only one instance. These and other wordly features remain to be investigated systematically. That findings as limited as ours could suggest such inquiries highlights the potential significance of further investigations of this kind. 


\section{APPENDIX}

\section{Pilot Experiments}

The pilot experiments involved a series of group meetings conducted under a single pattern of "experimenter induced" preferences. Figure 7 reports the payoffs and majority-rule rankings. We ran the meetings according to agendas described below.

In the first two experiments in this series (experiments 1 and 2), we used the same agenda (in abstract form) as the flying club had used. The outcome of both meetings was the alternative we predicted (Figure 8).

Experiments 3 and 4 used a different agenda designed to get the Condorcet winner, FFFA. ${ }^{*}$ The first vote in experiment 3 did not go as we predicted even though our model claimed a .91 probability (Figure 9). We believe this occurred because a straw vote was taken. Our model makes no allowances for straw votes, but our rules do not prohibit them. In experiment 4 , the group voted for FFFA, the predicted winner (Figure 9).

Of the remaining alternatives, only FFC and FFAA yielded agendas with "reasonable" strength according to our first model. The agendas for experiments 5 and 6 were designed to get FFC and FFAA respectively. Both meetings proceeded as expected (Figure 10).

These pilot experiments yielded a great deal of data on individual voting behavior. We used these results to estimate the probabilities needed for our subsequent experiments (Figure 6).

* Throughout the Appendix, the alternatives have an implicit EEE. That is, the Condorcet winner, FFFA, is actually EEEFFFA. 
Figure 7

Payoffs IN Dollars

\begin{tabular}{|c|c|c|c|c|c|c|c|c|}
\hline \multirow{2}{*}{ PERSON } & \multicolumn{8}{|c|}{ ALTERNATIVE } \\
\hline & FFFA & FFC & FFCC & FFAA & FFA & FFFC. & FFFF & FFF \\
\hline 1 & 8.00 & 6.00 & 5.50 & 5.00 & 1.00 & 0.75 & 0.25 & 0.50 \\
\hline 2 & 4.50 & 0.25 & 8.00 & 0.25 & 0.25 & 5.00 & 0.25 & 0.25 \\
\hline 3 & 0.45 & 8.00 & 7.90 & 0.29 & 0.49 & 7.80 & 0.40 & 0.55 \\
\hline 4 & 3.80 & 7.50 & 8.00 & 1.00 & 3.50 & 4.00 & 0.90 & 3.80 \\
\hline 5 & 8.00 & 2.00 & 6.00 & 8.00 & 5.00 & 7.00 & 4.00 & 3.00 \\
\hline 6 & 3.00 & 8.00 & 7.00 & 3.00 & 4.00 & 5.00 & 3.00 & 6.00 \\
\hline 7 & 7.00 & 6.00 & 8.00 & 7.00 & 6.00 & 6.00 & 5.00 & 4.00 \\
\hline 8 & 8.00 & 1.00 & 1.00 & 8.00 & 8.00 & 1.00 & 1.00 & 1.00 \\
\hline 9 & 8.00 & 1.00 & 6.00 & 7.00 & 3.00 & 4.00 & 5.00 & 2.00 \\
\hline 10 & 6.00 & 3.00 & 7.00 & 8.00 & 4.00 & 5.00 & 2.00 & 2.00 \\
\hline 11 & 8.00 & 7.50 & 7.00 & 6.00 & 7.40 & 2.00 & 2.00 & 1.00 \\
\hline 12 & 5.00 & 8.00 & 1.00 & 7.00 & 2.00 & 6.00 & 7.00 & 2.00 \\
\hline 13 & 8.00 & 6.00 & 2.00 & 3.00 & 5.00 & 1.00 & 7.00 & 7.00 \\
\hline 14 & 8.00 & 2.00 & 7.00 & 6.00 & 2.00 & 1.00 & 7.00 & 3.00 \\
\hline 15 & 8.00 & 7.00 & 4.40 & 3.60 & 7.00 & 2.00 & 2.00 & 1.00 \\
\hline 16 & 3.00 & 7.00 & 2.00 & 8.00 & 1.00 & 3.00 & $\because 00$ & 7.00 \\
\hline 17 & 7.00 & 2.00 & 6.00 & 5.00 & 8.00 & 3.00 & 7.00 & 1.00 \\
\hline 18 & 5.00 & 7.00 & 1.00 & 6.00 & 6.00 & 5.00 & 8.00 & 7.00 \\
\hline 19 & 8.00 & 7.00 & 6.00 & 5.00 & 6.00 & 1.00 & 1.00 & 7.00 \\
\hline $\begin{array}{l}\text { Majority rule } \\
\text { relation }\end{array}$ & $\underset{\text { first }}{1} \leftarrow$ & 2 & & 4 & cycle & & 7 & $\begin{array}{c}-8 \\
\text { last }\end{array}$ \\
\hline
\end{tabular}


Figure 8

Pilot Experiments 1 and $2 \dagger$

Experiment 1

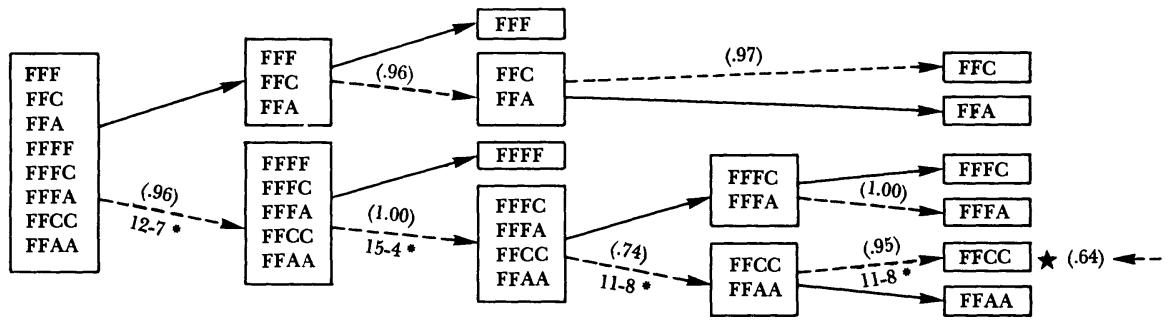

Experiment 2

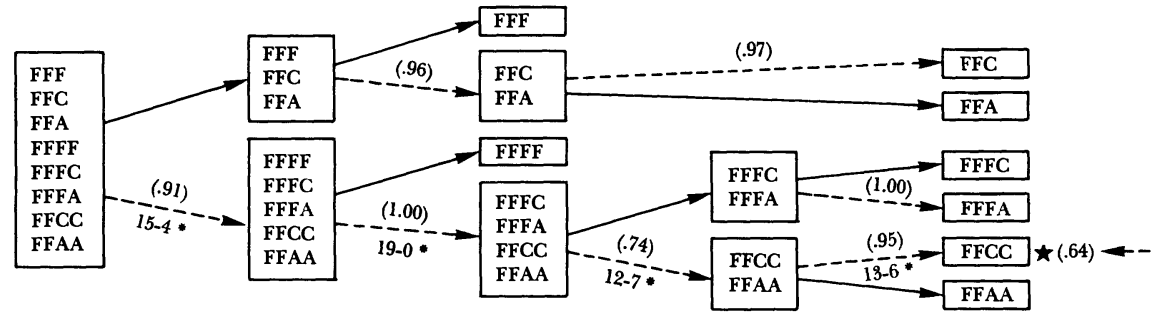

Experiments 1 and 2: Agenda

1. Shall the selection be a three-letter alternative or a four-letter alternative?

2. Shall the selection be a mixed-letter alternative?

3. If the selection is to be a four-letter, mixed-letter alternative, then shall it have two F's or three F's?

4. Shall the alternative have a $\mathrm{C}$ or an $\mathrm{A}$ ?

† For a key to the symbols in Figure 8, see Figure 6 supra. The alternatives in experiments 1 and 2 have an implicit EEE. For example, the alternative FFF is actually EEEFFF. 
Figure 9

\section{Pilot Experiments 3 and $4 \dagger$}

\section{Experiment 3}

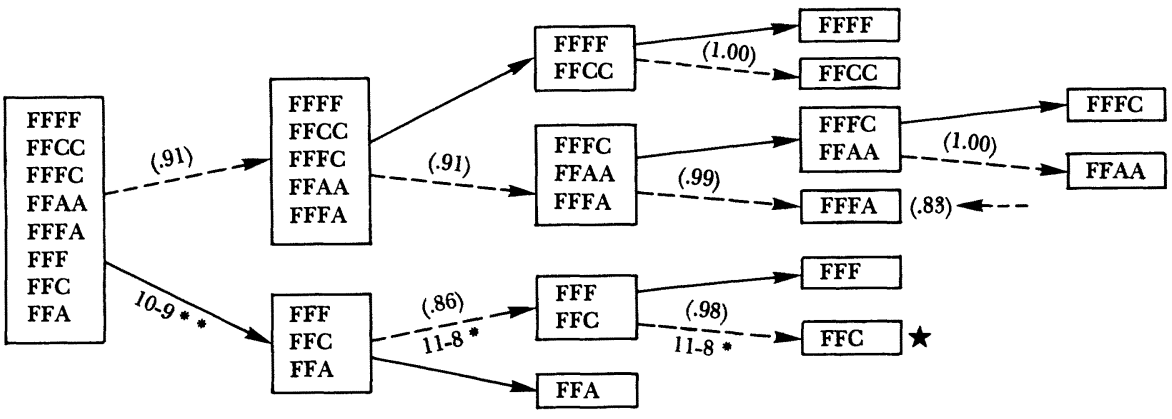

Experiment 4

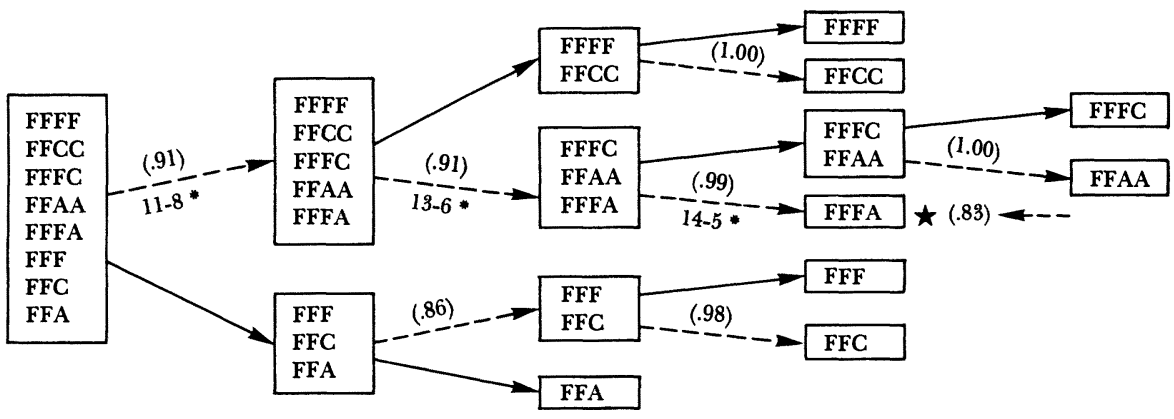

Experiments 3 and 4: Agenda

1. Shall the selection be a three-letter or a four-letter alternative?

2. From the four- or three-letter alternatives, shall the decision be from the first two or the remainder?

3. If only two alternatives remain, which shall be chosen? If more than two remain, shall the decision be from the first two or the remainder?

+ For a key to the symbols in Figure 9, see Figure 6 supra. The alternatives in experiments 3 and 4 have an implicit EEE. For example, alternative FFFF is actually EEEFFFF. 
Figure 10

Pilot EXPeriments 5 AND $6 \dagger$

Experiment 5

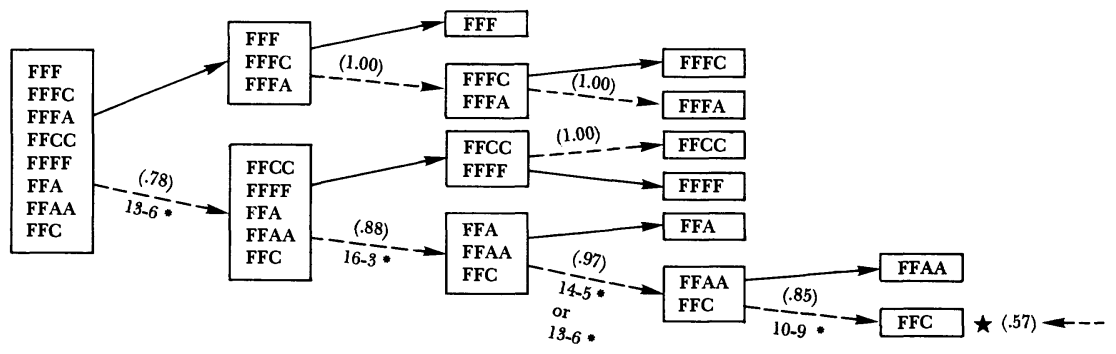

Experiment 5: Agenda

1. From these alternatives do we want one with at least three but no more than three F's?

2. Do we want a four-letter alternative which contains three or more F's or a C?

3. Do we want only one A?

\section{Experiment 6}

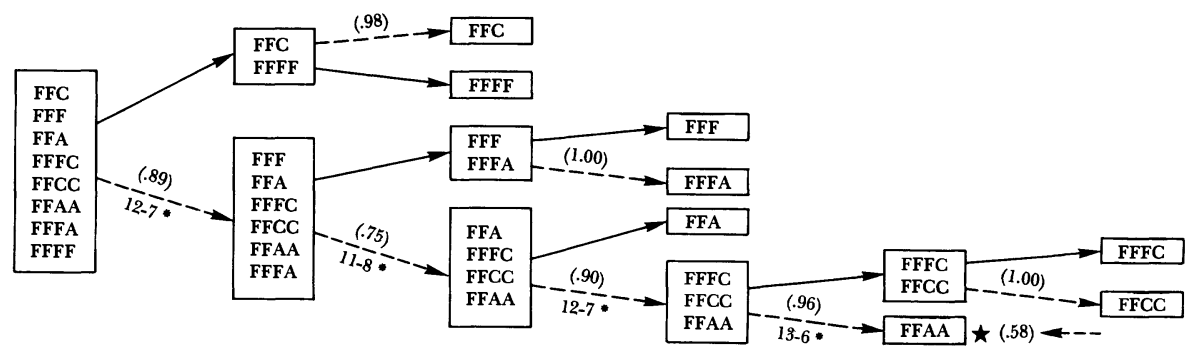

\section{Experiment 6: Agenda}

1. Shall we adopt one of the two extremes or eliminate them both?

2. Of those remaining shall we adopt one of the two extremes or eliminate them both?

3. Of those remaining shall we adopt the top alternative?

4. Of those remaining shall we adopt the bottom alternative?

5. Which of the two remaining shall we adopt?

† For a key to the symbols in Figure 10, see Figure 6 supra. The alternatives in experiments 5 and 6 have an implicit EEE. For example, alternative FFF is actually EEEFFF. 